\title{
Experimental Study of the Differential Effects of Playing Versus Watching Violent Video Games on Children's Aggressive Behavior
}

\author{
Hanneke Polman*, Bram Orobio de Castro, and Marcel A.G. van Aken \\ Developmental Psychology, Faculty of Social Sciences, Utrecht University, Utrecht, The Netherlands
}

\begin{abstract}
There is great concern about the effects of playing violent video games on aggressive behavior. The present experimental study was aimed at investigating the differential effects of actively playing vs. passively watching the same violent video game on subsequent aggressive behavior. Fifty-seven children aged 10-13 either played a violent video game (active violent condition), watched the same violent video game (passive violent condition), or played a non-violent video game (active non-violent condition). Aggression was measured through peer nominations of real-life aggressive incidents during a free play session at school. After the active participation of actually playing the violent video game, boys behaved more aggressively than did the boys in the passive game condition. For girls, game condition was not related to aggression. These findings indicate that, specifically for boys, playing a violent video game should lead to more aggression than watching television violence. Aggr. Behav. 34:256-264, 2008. (C) 2007 Wiley-Liss, Inc.
\end{abstract}

: : : : : : : : : : : : : : : : : : : : : : : : : : : : : : : : :

Keywords: aggressive behavior; aggression; violent video games; violent television

\section{INTRODUCTION}

The significant presence of new media, such as television and video games, in the lives of children and adolescents is apparent. Children spend a great deal of time watching television and playing video games. In one study it was found that children spend an average of $25 \mathrm{hr}$ a week watching television and $9 \mathrm{hr}$ a week playing video games [Gentile et al., 2004]. The time children spend on these new media is ten times as much as the time they spend on, for instance, reading for pleasure. The violent nature of the television programs and video games to which children are exposed is of specific concern. Several studies indeed show that children are exposed to a substantial amount of violence in these new media. In a survey by Buchman and Funk [1996], fourth- to eight-graders preferred violent video games to other video games. Also, young children come across a broad variety of violent acts when they are watching television [Connor, 2002].

The possible negative effects of watching violent television programs and playing violent video games have been studied extensively. A metaanalytic review by Paik and Comstock [1994] on the relationship between violent television programs and antisocial behavior shows a significant relation $(r=.31)$. A meta-analysis by Anderson [2004] reveals a somewhat smaller relationship between exposure to violent video games and increase in aggressive behavior $(r=.26$ for studies without methodological flaws and $r=.14$ for other studies).

On theoretical grounds one may expect violent video games to lead to higher levels of aggression than violent television programs. According to the social learning theory [Bandura, 1994], in playing a violent video game participant modeling is assumed, in which the person playing a video game virtually becomes the character of the video game [Schutte et al., 1988]. Owing to the direct control over the character's behavior, a larger effect is expected for video game violence than for television violence. Moreover, violent video game players are directly

\footnotetext{
*Correspondence to: Hanneke Polman, Developmental Psychology, Faculty of Social Sciences, Utrecht University, P.O. Box 80140, 3508 TC Utrecht, The Netherlands. E-mail: j.d.m.polman@uu.nl
}

Received 6 December 2006; Revised 25 November 2007; Accepted 25 November 2007

Published online 27 December 2007 in Wiley InterScience (www. interscience.wiley.com). DOI: 10.1002/ab.20245 
rewarded for their acts of aggression in terms of an extra life, a musical interlude, or a high score. The reinforcing effects of aggression in violent video games may thus instigate the use of aggression in real life.

The aim of this study is to address the question whether the active involvement of playing a violent video game leads to more aggression than the passive observation of watching the same violence on screen. Contrasting these two situations can be translated to a comparison between television and video game violence.

Several studies directed at investigating possible differences between aggression after watching violent television programs and playing violent video games have found no differences in aggressive behavior [Graybill et al., 1987; Meyers, 2003; Silvern and Williamson, 1987]. The apparent inability to detect these differences may have resulted, however, from several limitations. For instance, the study by Silvern and Williamson [1987] did not match the violent video game and television program on important factors such as action, pauses, difficulty, entertainment, and frustration [Anderson and Ford, 1986]. However, these factors may influence the gamers' level of enjoyment, involvement, and activity. In case of a highly enjoyable and involving violent game opposed to a very dull nonviolent game, the levels of activity required in the violent game itself can lead to higher levels of aggression. This problem can be overcome by matching the violent and non-violent video game on these important dimensions.

Also, these studies - and experimental research on the relationship between violent video games and aggressive behavior in general - are characterized by the absence of peer evaluations of aggression. Because of high levels of exposure to, and involvement with the behavior of their aggressive age mates, peers may be better judges of aggressive behavior than parents and teachers. Parents and teachers may experience more difficulty in discriminating between war play and rough and tumble play on one hand and aggression on the other hand [Goldstein, 1998]. Peers can provide better information on the intent of the display of presumed aggression.

Another shortcoming in research investigating the relationship between violent video games and aggression is their use of correlational designs. These designs only allow for the ascertainment of an association between violent video games and aggression. This type of research, however, does not allow establishing causality. Experimental designs in which children are randomly assigned to different game conditions are urgently called for.

More conclusive comparative evidence concerning the effects of television violence and video game violence on aggressive behavior can be obtained by experimentally comparing the effects of passively watching television violence and actively playing a game involving the same violence. Therefore, in this study three different game conditions were investigated: an active violent condition in which a violent video game was played, a passive violent condition in which the same violent video game was observed, and an active non-violent condition in which a nonviolent video game was played. The children were randomly assigned to different game conditions (active violent, passive violent, active non-violent) to ensure that all the game conditions contained the same number of aggressive and non-aggressive children. Possible differences in aggression after the manipulation, therefore, cannot be attributed to pre-existing differences in aggression.

Also, to overcome some of the shortcomings of other studies, we selected a violent and a non-violent video game different in violent content, but equivalent to earlier mentioned possibly confounding elements according to the results of a preliminary study. In addition, aggressive behavior was assessed with peer nominations of real-life aggressive behavior. To our knowledge, this is the first experimental study on the relationship between violent video game play and aggression that measures aggression in this manner. This type of measurement tells us more about the actual occurrence of aggressive acts.

In sum, this study aimed to assess whether the active involvement of playing a violent video game leads to more aggression than the passive observation of watching the same violent video game. It was hypothesized that playing a violent video game will lead to higher levels of aggression than watching a violent video game or playing a non-violent game. As previous experiments have produced mixed results regarding potential gender differences in the influence of violent video games [Bartholow and Anderson, 2002], gender differences were examined.

\section{METHODS}

\section{Design}

The design in this study was a randomized-blocks 3 -group between-subjects experiment, with game condition as the independent variable and aggressive behavior as the dependent variable. 


\section{Participants}

Participants were recruited from four classrooms of two schools in The Netherlands. Schools were located in small and medium-sized towns in two different regions. All parents $(n=102)$ were asked for permission to let their children enter the study. Parents were informed of the purpose of the study and were asked not to communicate this to their children. There were 57 children $(56 \%)$ for whom permission was obtained to participate in the entire study. For three additional children permission was given only to complete a questionnaire on aggressive behavior. One boy in the passive game condition was excluded from data analyses as he was unwilling to cooperate. All descriptives and analyses were performed with 56 children, 28 boys, and 28 girls.

Thirty-eight $(68 \%)$ children were in fifth, and 18 $(32 \%)$ children were in sixth grade. In both the grades there was an equal number of boys and girls. Age varied from 10 to 13 years. Most children were 10 years old $(n=25)$. There were also several 11 year olds $(n=23), 12$ year olds $(n=7)$, and 13 year olds $(n=1)$.

Children were approximately equally distributed across game conditions. The active violent condition $(n=20)$ contained 8 boys and 12 girls, the passive violent condition $(n=17)$ had 10 boys and 7 girls, and the active non-violent condition $(n=19)$ had 10 boys and 9 girls.

It appeared that most children $(68 \%)$ were unaware of the purpose of the study. Children frequently thought that the research either dealt with video games $(14 \%)$, aggression $(36 \%)$, or video games and aggression without integrating both topics $(5 \%)$. Several children $(13 \%)$ had no idea what the research topic was. However, there was a substantial group of children $(32 \%)$ who knew that the research dealt with the effects of playing violent video games on aggressive behavior. Fortunately, children's knowledge of the purpose of the study was equally distributed across game conditions, $\chi^{2}(2, N=56)=0.97, P=.61$, and was not different for boys compared with girls, $\chi^{2}(1, N=56)=1.31$, $P=.25$. Also, a Kruskal-Wallis test revealed that children's knowledge of the purpose of the study was not predictive of children's aggressive behavior during the free play session, $\chi^{2}(1, N=56)=0.60$, $P=.44$.

\section{Procedure}

The study was conducted at participants' schools and was introduced to the children as a study on their skills and frequency of gaming behavior. It was explained that the study involved different video games and different levels of activity (playing or watching). Blocks of three children were randomly selected and formed from a list of participating children and asked to leave the classroom together to participate in the study. However, on three instances, children could not be grouped by three because the class size was not divisible by three. For this reason, two children were paired by two and one child was not paired. As they were randomly selected across all children in the classroom, the groups could be either same sex or mixed sex. The three children in each block were then randomly distributed across the three game conditions (active violent, passive violent, active non-violent condition), according to a numbered piece of paper they picked. This procedure was used to emphasize the random assignment to game condition. Children in the active violent condition played a violent video game and children in the passive violent condition watched this game being played on a television screen. A screen separated the children in the active and passive conditions from each other. Children in the active non-violent condition played a non-violent video game in a separate room.

The purpose of the violent game was explained to children in the active violent and passive violent game conditions. To warrant an optimum resemblance between watching a violent video game (passive violent game condition) and watching television, contact between participants was prevented. The children in the passive condition were told to pay attention to the character that was chosen by the child in the active violent condition and to observe this character closely throughout the game. After $15 \mathrm{~min}$ the children in all the game conditions were asked to stop their activities and fill in a questionnaire on their gaming habits.

Two free play sessions with all the children in the classroom were held consecutively, one in the morning (as is regular practice in Dutch classrooms) and one in the afternoon (additional, for the sake of this study). Playtime normally occurred outside on the schoolyard. However, as the result of bad weather conditions, on two occasions a play session was held inside the classroom. At the time of the free play session some children had played a video game a moment ago and others had played a game at the very most $3 \mathrm{hr}$ earlier. It was coded whether children played the game and immediately went out to the playground $(n=18)$, played the game approximately half an hour until $1 \mathrm{hr}$ earlier $(n=18)$, or played the game more than an hour earlier $(n=20)$. 
At the end of each day, children who had permission completed a questionnaire on aggressive behavior, in which they were asked to name children who displayed certain forms of aggressive behavior that day (see measures). After the experiment was completed, children were informed about the true purpose of the study and the reason for not informing them on this matter beforehand.

\section{Apparatus}

The study made use of two 20-in television screen each connected to a Sony playstation. The games involved in the study were selected through preliminary analyses involving 15 Dutch students (11 women and 4 men) at Utrecht University. The goal of the preliminary analyses was to select two video games different in violent content, but comparable in levels of action, pauses, difficulty, entertainment, and frustration. Each student played three violent and three non-violent video games on a Sony play station connected to a 20 -in television screen. The violent video games were Tekken 3, Medal of Honor (Allied Assault), and James Bond (Tomorrow Never Dies). The non-violent games were Crash Bandicoot 2, Gran Turismo 2, and Tony Hawk Proskater. Each game was played for approximately $10 \mathrm{~min}$. After each game, participants were asked to rate the game on the dimensions of violent content, action, pauses, difficulty, entertainment, and frustration taken from Anderson and Ford [1986]. Five-point rating scales were used, ranging from (1) totally agree to (5) totally disagree. Mean ratings for all the games on all dimensions are presented in Table I.

To test for differences between video games on the six dimensions within-subject analysis of variances were conducted, with game as within-subject factor and violence, action, pauses, difficulty, entertainment, and frustration as dependent variables. As expected, the video games differed in violence, $F(5,70)=83.64, P<.001$. There were no significant differences in frustration between the different games, $F(5,70)=1.91, P=.10$. However, the dimensions action, $F(5,70)=2.34, P=.01$, pauses, $F(5,70)=2.48, P=.04$, difficulty, $F(5,70)=5.30$, $P<.001$, and entertainment, $F(5,70)=10.13$, $P<.001$ differed across the different games.

Post-hoc analyses revealed that there were no pairs of violent and non-violent games exactly equivalent on all the dimensions action, pauses, difficulty, entertainment, and frustration. Of the two most equivalent pairs, the video games Tekken and Crash Bandicoot differed the most in violence $(D=3.47)$, and were relatively similar in action, pauses, difficulty, entertainment, and frustration. Therefore, in this study Tekken was selected as the violent and Crash Bandicoot as the non-violent video game.

\section{Measures}

Gaming habits. After the experiment, children were asked to complete a questionnaire on their gaming habits. The questions were regarding frequency of gaming, familiarity with the game used in the study, and favorite video games. Frequency of gaming was measured with a 5-point scale ranging from (1) almost never to (5) once or more per day, and familiarity with the game with a 3-point scale ranging from (1) almost never to (3) often. Favorite video game was measured with an open-ended question. Answers were classified on violence according to the rating system of the Entertainment Software Rating Board (http://www.esrb.org, retrieved December 2005). Categories were (0) no

TABLE I. Means and Standard Deviations on Six Rating Dimensions.

\begin{tabular}{|c|c|c|c|c|c|c|c|c|c|c|c|c|}
\hline \multirow[b]{3}{*}{ Video Game } & \multicolumn{12}{|c|}{ Dimensions } \\
\hline & \multicolumn{2}{|c|}{ Violence } & \multicolumn{2}{|c|}{ Action } & \multicolumn{2}{|c|}{ Pauses } & \multicolumn{2}{|c|}{ Difficulty } & \multicolumn{2}{|c|}{ Entertaining } & \multicolumn{2}{|c|}{ Frustration } \\
\hline & $M$ & SD & $M$ & $\mathrm{SD}$ & $M$ & SD & $M$ & $\mathrm{SD}$ & $M$ & SD & $M$ & SD \\
\hline Crash Bandicoot* & 1.00 & 0.00 & 4.13 & 1.06 & 1.80 & 0.94 & 3.13 & 0.74 & 4.47 & 0.52 & 3.07 & 1.28 \\
\hline Gran Turismo & 1.27 & 0.59 & 3.67 & 1.35 & 1.67 & 0.82 & 3.60 & 0.91 & 3.53 & 1.30 & 3.00 & 1.25 \\
\hline Tony Hawk & 1.93 & 1.10 & 3.93 & 1.10 & 2.33 & 0.98 & 3.73 & 1.16 & 4.07 & 0.80 & 2.40 & 1.18 \\
\hline James Bond & 4.40 & 1.06 & 4.07 & 0.70 & 2.27 & 0.80 & 3.53 & 1.25 & 2.53 & 1.06 & 3.53 & 0.99 \\
\hline Tekken* & 4.47 & 1.06 & 4.53 & 0.64 & 2.27 & 1.28 & 2.20 & 1.01 & 3.93 & 1.22 & 3.27 & 1.28 \\
\hline Medical of Honor & 4.67 & 0.49 & 3.53 & 1.06 & 2.53 & 1.25 & 3.07 & 1.10 & 2.60 & 1.24 & 3.07 & 1.53 \\
\hline
\end{tabular}

Note: Means are based on the judgment of 15 students. Games are ranked from least to most violent. A high score on any of the dimensions indicates the video contains high levels of this dimension.

* Selected games based on student ratings. 
violence, (1) mild fantasy violence/mild cartoon violence/mild animated violence/mild violence, (2) fantasy violence/cartoon violence/animated violence, (3) violence/intense violence/realistic violence. The first three games children mentioned were double coded $(81 \%$ of all the games children reported on). Excellent interrater agreement was obtained $(\kappa=.82)$. A mean favorite violent video game score was computed by averaging violence classifications of all favorite video games (ranging from 0 to 3 ).

Frequency of gaming and mean favorite violent video game was correlated significantly, $r=.49$, $P<.001$. Children playing often, predominantly played violent video games, whereas children who played infrequently mostly played games with no violence or mild levels of violence. Frequency of gaming was multiplied with mean favorite violent video game. This variable "violent gaming frequency" was used to estimate the amount of violent video games children played. Scores varied from (0) never playing violent video games to (15) exclusively playing violent video games on a daily basis.

Aggression. Children with permission to enter the study were asked to name children who had displayed acts of physical, verbal, or relational aggression that day. Peer nominations for aggressive behavior have been used extensively [Björkvist et al., 1992; Crick and Grotpeter, 1995; Werner and Crick, 1999] since they were originally developed by Eron et al. [1971]. The six items used in this study taken from research by Bons [2003] were "hit, kick, or push someone," "fight with someone," "name calling or have a quarrel," "tease someone," "frighten someone off to get what he/she wanted," and "gossip." Furthermore, children were asked to evaluate the intentions for aggressive act. They indicated whether they thought the act was intended as a joke or deliberately hostile. Aggression intended as a joke can be seen as a form of roughand-tumble play, which is a social activity enjoyed by all parties. In accordance with current definitions of aggression, this social engagement is not considered aggressive behavior in this study [see also Anderson and Bushman, 2002]. Acts were only coded as aggressive if they were said to be deliberately hostile and appeared in the first play session after the child had played the video game. For children who had played a video game in the morning, only the aggressive acts rated as hostile in the first play session were used in analyses. For children who had played in the afternoon, only deliberate hostile aggression in the afternoon play session was used in analyses.
For each child in the study, for each of the six aggression items, the number of aggressive incidents reported on by children in the peer nomination procedure was divided by the number of nominators. The resulting six scores were summed up to create a reliable overall aggression scale $(\alpha=.74)$. The reliability of this scale was comparable to the internal consistency found in earlier research $(\alpha=.72)$ by Bons [2003]. However, the distribution of aggression scores on this interval scale was positively skewed, thereby not allowing for parametric analyses. Therefore, non-parametric tests were used to analyze the data. Individual scores were converted into rank scores, with a score of 1 indicating the most aggressive behavior.

\section{RESULTS}

\section{Preliminary Analyses}

First, it was investigated whether children in the different game conditions differed in violent gaming frequency and familiarity with the video game in the study, and whether there were any gender differences. Also, whether violent gaming frequency was related to aggressive behavior was examined.

A strong significant relationship between gender and violent gaming frequency was found, $F(1$, $54)=19.15, P<.001$. Boys played considerably more violent video games than girls. There were no differences in violent gaming frequency across game conditions; children in the active violent, passive violent, and active non-violent game condition played equal amounts of violent video games, $F(2$, $53)=0.57, P=.57$. There was no significant correlation between violent gaming frequency and aggressive behavior on the playground, $r_{s}=.20, P=.15$.

There was a significant association between gender and familiarity with the game in the study, $F(1,54)=11.70, P<.01$. In general, boys were more familiar with the video game they played than girls. Children in the active violent, passive violent, and active non-violent game condition did not differ in familiarity with the game being played, $F(2,53)=1.17, P=.32$. A Kruskal-Wallis analysis revealed that in this sample gender was not related to playground aggression, $\chi^{2}(1, N=56)=0.52$, $P=.47$.

\section{Effect of Game Condition on Aggression}

As is typical in studies of aggression, the data were analyzed separately for males and female subjects. Although the design was a randomized blocks 


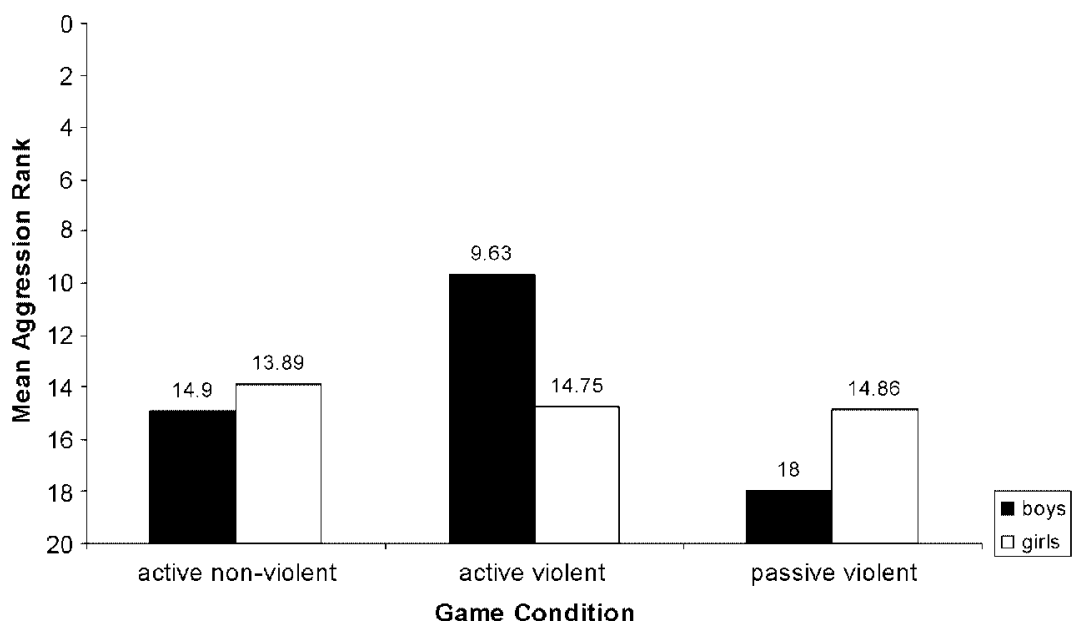

Fig. 1. Mean aggression rank by game condition and gender.

design, the groups were compared with independent groups tests because the blocking was at random. Analyzing males and females separately would have been difficult with blocking included in the analysis. Also, the independent groups analysis is a conservative (if less powerful) test of significance in this case. As is visible in Figure 1, there was a significant relationship between game condition and aggressive behavior for boys, $\chi^{2}(2, N=28)=8.03, P=.02$. To investigate the difference in effect in more detail, separate Kruskal-Wallis tests were conducted, comparing each game condition with each other. Boys in the active violent game condition were more aggressive than boys in the passive violent game condition, $\chi^{2}(1, \quad N=18)=7.92, \quad P=.01$. However, there was no significant difference in aggressive behavior between boys in the active violent and boys in the active non-violent condition, $\chi^{2}(1, N=18)=2.01, P=.16$. There was also no significant difference between boys in the active nonviolent condition and the passive violent condition, $\chi^{2}(1, N=20)=2.11, P=.15$, and the difference in means was opposite to what would have been predicted. One should note, however, that the lack of significance in these two cases should not be taken as proof of no difference between the conditions given the small sample sizes and the low power of the independent groups $\chi^{2}$ test.

For girls, there was no relationship between game condition and aggressive behavior, $\chi^{2}(2$, $N=28)=0.17, \quad P=.92$. As can be seen in Figure 1, girls in the active violent, passive violent, and active non-violent game condition did not differ significantly in aggressive behavior. As with the boys, however, this lack of significance should not be taken as proof of no difference between the conditions for females given the small sample sizes and the low power of the independent groups $\chi^{2}$ test.

\section{Duration of Effect}

It was investigated how long lived the effect of game condition on aggressive behavior was. As the effect of game condition on aggressive behavior was only found for boys in the active violent game condition in comparison to the passive violent game condition, it was decided to exclusively look at the duration of this effect for boys in these violent video game conditions. Even though statistical power was low because of the small sample size, a time effect was found. A Kruskal-Wallis test with time as the independent and aggressive behavior as the dependent variable revealed that boys who had just played or watched a violent video game were more aggressive (mean rank $=4.50$ ) than boys who played approximately an hour (mean rank $=12.00$ ) or more than an hour ago (mean rank $=10.13), \chi^{2}(2$, $N=18)=7.92, P=.02 .{ }^{1}$

\footnotetext{
${ }^{1}$ In an additional search for mediation, we tried to measure experienced frustration, general arousal, and modeling by asking children to rate their agreement with the following statements: "I felt disappointment when things did not go so well," "I felt tension in my body during the game," and "I was so taken up by the game, I felt I was turning into the character on screen." For boys, there were only differences in frustration. Boys in the active violent condition ( $M=3.63, S D=1.30)$ were more frustrated than boys in the active non-violent $(M=2.00, \quad S D=1.15) \quad$ condition, $F(2,25)=3.50$, $P=.05$. There were, however, no mediational effects. Frustration did not have an effect while controlling for game condition [Kenny et al., 1998] in a binary logistic regression, when adding game condition (dummy coded for active violent) in block 1 and frustration in block $2, \chi 2$ block $2(1, N=28)=0.90, P=.34$.
} 


\section{DISCUSSION}

This study aimed to test the differential effects of playing vs. watching a violent video game on real-life aggressive behavior. Playing a violent video game caused boys to become more aggressive than merely watching the same violent video game. Active participation of actually playing the violent video game made boys behave aggressively more often than passively watching violence, as is the case in television. However, these results are complicated by the fact that there were no significant effects for girls and by the facts that for boys neither the active playing of violent games nor the passive viewing of violent games stimulated significantly more aggression than did the active playing of non-violent games.

This is the first experimental study to find significant differential effects of playing vs. watching violent video games on real-life aggressive behavior. Earlier research comparing these differential effects did not find any differences. Those studies, however, did not use peer nominations of real-life aggressive behavior and did not match the violent and nonviolent game on important possibly confounding factors. In this study, these shortcomings were overcome as aggressive behavior was measured in a real-life setting with a pair of matched video games.

The gender difference in the relationship between game condition and aggression may be partially because of differences in children's daily activities. Boys in this study played a lot of violent video games in real life and behaved aggressively after playing a violent video game, whereas girls did not play these games and did not behave aggressively after playing a violent video game. Perhaps the effect is specific for boys, because the active violent condition may have activated pre-existing violence schemata that they had previously acquired through frequent game playing [Polman and Orobio de Castro, 2006]. These schemata are thought to exist in children who repetitively play violent video games. Playing a game with violent content may activate these pre-existing aggressive schemata [see also Anderson and Dill, 2000]. Almost all boys were frequent players and may thereby have acquired such schemata. This activation seems to be short lived and may lead to a heightened likelihood of becoming aggressive in the playground. In contrast, girls played less video games in daily lives. Therefore, no schemata could be activated by playing a violent video game only once. Thus, boys who have played more violent games and have more aggressive schema are more affected by playing.
This line of reasoning is still speculative and may be investigated in more detail in future research.

It is impressive that the effect of game playing on aggression by boys was so strong that it could be detected with this limited sample size in a brief play session. The resulting low statistical power was only sufficient to detect large effects. For this reason, small to moderate group differences may not have been detected. Thus, we cannot conclude that there are absolutely no effects for females. The effects may just be undetectable with small samples. Also, the fact that there were no significant differences between boys in the active violent video game condition and boys in the active non-violent videogame condition may be attributable to the weak power of the significance tests. Additional studies involving larger samples are needed to enable the finding of possible small to moderate effects on aggression and possible moderator and mediator effects.

A strength of this study is that it made use of peer nominations as a measure of aggression to stay close to actual aggressive behavior. This measurement concerned real-life acts of aggression as opposed to the laboratory measurements predominantly used in research concerning the relationship between video games and aggressive behavior. For these reasons, this type of measurement offers great insight into the actual occurrence of aggressive acts.

This study was successful in creating three game conditions similar on important dimensions. The active violent and passive violent conditions made use of the same video game that differed only on violent content from the non-violent video game. Therefore, the difference in aggression between boys playing a violent video game and watching a violent video game cannot be attributed to differences in important dimensions in these video games. Also, these differences did not exist between the video game in the active non-violent game condition and the video game in the active violent and the passive violent game condition. Preliminary analyses were conducted to select video games that differed in their levels of violence but were equivalent to the dimensions action, pauses, difficulty, entertainment, and frustration. Differences in aggression between boys playing a violent and playing a non-violent video game cannot be the result of differences in games.

Some limitations of the study should be noted. If findings are to be generalized to television violence, it should be kept in mind that television violence was 
measured by watching a violent video game on screen. Some limitations concerning this operationalization exist. First, children were aware they were watching a video game and not a television program. Second, the video game graphics are less realistic than television graphics. Nonetheless, we think that earlier mentioned benefits concerning the equivalence on important dimensions outweigh the limitations of this type of operationalization.

A limitation regarding the type of aggression measurement should also be noted. During free play, some children might have come across provocative situations whereas others did not enter these situations. This possibility was not taken into account in this study. On the basis of chance, one may expect equal opportunities for children in different game conditions to come across such situations. Still, future research may experimentally manipulate the possibility to behave aggressively (by provoking or not provoking participants) to investigate the relationship between violent video games and aggression.

Also, it might have been informative to include a passive non-violent game condition. Including a passive non-violent game condition may have solved the question whether aggression after playing a video game is attributable to the activity of playing a game, irrespective of any violent content. That is, frustration-aggression and general arousal theory both suggest that children playing a non-violent video game would be more aggressive than children watching a non-violent video game. According to the principles of social learning theory, one may expect no aggression in both conditions because of the absence of violent models. The addition of a passive non-violent condition would have shed more light on the specific effects of violence and activity of playing a game. However, the addition of a fourth game condition would have led to reduced power. Future research with a larger sample size may include a passive non-violent game condition.

A question that remains unanswered is which children become more aggressive after playing a violent video game. Future studies should investigate more child and environmental characteristics that could moderate the effect of violent video game play on aggression.

Future experimental studies regarding violent video game play and aggression involving child participants should not only investigate whether violent video games lead to aggression but also why they do so. Special focus should regard possible mediating variables. This study found no mediating effects for frustration, general arousal, and modeling. A more extensive investigation of these possible mediating variables might give us more conclusive information regarding underlying theoretical mechanisms when explaining aggressive behavior. One may also look at other possible mediating variables such as the priming of (implicit) cognitions. Research with young adults has indeed found that playing violent video games leads to a bias for aggression-related implicit cognitions [Kirsh et al., 2005]. Whether this effect also operates for children is unclear. Furthermore, it seems of much use to study which types of aggression are activated by playing violent games. Do children become predominantly proactive aggressive because they learn that the use of aggression in video games is beneficial? Or do children become reactively aggressive as they are frustrated by video games and want to take revenge? Whether different types of video games specifically elicit reactive or proactive aggression would provide strong indications for the mediational mechanisms.

The findings of this study are highly relevant for the social debate on the regulation of availability and supervision of violent video games. The current concerns about the possible effects of violent video games are supported by empirical evidence. Boys playing violent video games behaved more aggressively later that day than boys watching violent video games. The effect of violent video games on aggression appears to be bigger than the effect of televised violence. Therefore, teachers and caregivers may need to pay special attention to the regulation of children's violent video game play.

\section{REFERENCES}

Anderson CA. 2004. An update on the effects of playing violent video games. J Adolesc 27:113-122.

Anderson CA, Bushman BJ. 2002. Human aggression. Annu Rev Psychol 53:27-51.

Anderson CA, Dill KE. 2000. Video games and aggressive thoughts, feelings, and behavior in the laboratory and in life. J Pers Soc Psychol 78:772-790.

Anderson CA, Ford CM. 1986. Affect of the game player: Short term effects of highly and mildly aggressive video games. Pers Soc Psychol Bull 12:390-402

Bandura A. 1994. The social cognitive theory of mass communication. In: Bryant J, Zillmann D (eds): Media Effects: Advances in Theory and Research. Hillsdale, NJ: Erlbaum, pp 61-90.

Bartholow BD, Anderson CA. 2002. Effects of violent video games on aggressive behavior: Potential sex differences. J Exp Soc Psychol 38:283-290.

Berkowitz L. 1989. Frustration-aggression hypothesis: Examination and reformulation. Psychol Bull 106:59-73. 
Björkvist K, Lagerspetz KMJ, Kaukiainen A. 1992. Do girls manipulate and boys fight? Developmental trends in regard to direct and indirect aggression. Aggr Behav 18:117-127.

Bons EM. 2003. Aggressive children and path. A study on the relation between the quality of path and the effectiveness of the programme. Unpublished master's thesis, Utrecht University, Utrecht, The Netherlands.

Buchman DD, Funk JB. 1996. Video and computer games in the '90s: Children's time commitment and game preference. Child Today 24:12-16.

Connor DF. 2002. Aggression and Antisocial Behavior in Children and Adolescents. Research and Treatment. New York: The Guilford Press.

Crick NR, Grotpeter JK. 1995. Relational aggression, gender, and social psychological adjustment. Child Dev 66:710-722.

Eron LD, Walder LO, Lefkowitz MM. 1971. Learning of Aggression in Children. Boston: Little, Brown.

Gentile DA, Lynch PJ, Linder JR, Walsh DA. 2004. The effects of violent video game habits on adolescent hostility, aggressive behaviors, and school performance. J Adoles 27:5-22.

Goldstein JH. 1998. Immortal kombat: War toys and violent video games. In: Goldstein JH (ed): Why We Watch: The Attractions of Violent Entertainment. New York: Oxford University Press, pp 53-68.

Graybill D, Strawniak M, Hunter T, O'leary M. 1987. Effects of playing versus observing violent versus nonviolent video games on children's aggression. Psychol A Q J Hum Behav 24:1-8.
Kenny DA, Kashy DA, Bolger N. 1998. Data analysis in social psychology. In: Gilbert D, Fiske S, Lindzey G (eds): The Handbook of Social Psychology. Boston, MA: McGraw-Hill, pp 233-265.

Kirsh SJ, Olczak PV, Mounts JRW. 2005. Violent video games induce an affect processing bias. Media Psychol 7:239-250.

Meyers KS. 2003. Television and video game violence: Age differences and the combined effects of passive and interactive violent media. Dissertation Abstr Int 63:5551 (UMI No. 3069723).

Paik H, Comstock G. 1994. The effects of television violence on anti-social behavior: A meta-analysis. Commun Res 21: 516-546.

Polman H, Orobio de Castro B. 2006. Violent video game playing effects on reactive and proactive aggression. Paper presented at the XVIIth World Meeting of the International Society for Research on Aggression, Minneapolis.

Schutte NS, Malouff JM, Post-Gorden JC, Rodasta AL. 1988. Effects of playing video games on children's aggressive and other behaviors. J Appl Soc Psychol 18:454-460.

Silvern SB, Williamson PA. 1987. The effects of video game play on young children's aggression, fantasy, and prosocial behavior. J Appl Dev Psychol 8:453-462.

Werner NE, Crick NR. 1999. Relational aggression and socialpsychological adjustment in a college sample. J Abnorm Psychol 108:615-623. 